\title{
Supplementation of Infant formula with probiotics, prebiotics, DHA \& ARA: A systematic review
}

\author{
Tambakhe M. K., Pawar P. A." \\ Department of Chemical Technology, Sant Gadge Baba Amravati University, Amravati, Maharashtra, India, 444602
}

Email address:

mk2tambakhe@gmail.com (Tambakhe M. K.), pradippawar@sgbau.ac.in (Pawar P. A.)

To cite this article:

Tambakhe M. K., Pawar P. A.. Supplementation of Infant Formula with Probiotics, Prebiotics, DHA \& ARA: A Systematic Review. Journal of Food and Nutrition Sciences. Vol. 2, No. 4, 2014, pp. 185-194. doi: 10.11648/j.jfns.20140204.24

\begin{abstract}
There are recommendations to guide parents to help their infants make the transition from milk to weaning foods, but they differ in their focus in developed or developing countries and on the physiological and behavioral reasons that underlie the introduction of weaning foods. According to recommendations, ideally, term infants should begin weaning at six months, while breastfeeding should continue for two years. The recommendations on nutrients in complementary foods are based on the nutrient gap between the composition and volume of breast milk after approximately six months of exclusive breastfeeding and the physiology of infant nutritional requirements. Gastrointestinal flora influences health, but the composition of flora can be changed with prebiotics or probiotics. The addition of probiotics to powdered infant formula has not been demonstrated to be harmful to healthy term infants. ESPGHAN Committee on Nutrition reviews the effect of adding probiotic bacteria to infant formulas, follow-on formulas and special medical foods. The administration of probiotic (single or in combination) supplementation in infant or follow-on formula, and given beyond early infancy, may be associated with some clinical benefits, such as a reduction in the risk of nonspecific gastrointestinal infections, a reduced risk of antibiotic use and a lower frequency of colic and irritability. The addition of prebiotics to infant formula softens stools but other putative effects remain to be demonstrated. Studies published post marketing shows that infant fed a longchain inulin/galactooligosaccharide mixture $(0.8 \mathrm{~g} / \mathrm{dl})$ in formula normally have no side - effects. The addition of same mixture at a concentration of $0.8 \mathrm{~g} / \mathrm{dl}$ to infant formula was therefore recognized as safe by European Commission in 2001 but follow - up studies were recommended. It is thought that a bifidogenic effect is beneficial for the infant host. The rising incidence in allergy during the first year of life may justify the attempts to modulate the infant's formula. In addition to prebiotic and probiotic, DHA and ARA are important for brain and eye development. Many researchers have demonstrated the role of DHA and ARA in infant health and development.
\end{abstract}

Keywords: Weaning, Probiotic, Prebiotic, DHA, ARA

\section{Introduction}

Breast-feeding is considered best for infants, from nutritional and immunological points of view as well as for protection against e.g. Campylobacter associated diarrhoea [28]. However, time constraints and urbanisation [1] are factors associated with early termination of breast-feeding. In addition, infants require complementary feeding from around the age of 4-6 months[42]. A gradually increasing provision of complementary (weaning) food causes a concomitant reduction in the child's dependence on breast milk; this reduction continues until the child can fulfil all his or her nutritional needs with an adult diet. Apart from nutritional concerns, the development of certain physical skills (the chewing and swallowing of relatively large quantities of solid food) determines the type of food that is appropriate at a particular age; the most problematic age is about 9-12 months, when an already considerable nutritional demand coincides with a still limited stomach capacity [41].

The World Health Organization (WHO) recommends exclusive breastfeeding until six months of age and continued breastfeeding for two years, together with the timely introduction of adequate amounts of safe and suitable complementary foods. At six months of age, complementary foods are introduced because breast milk no longer meets the nutritional requirements of the child [82]. By the end of the first year, infants should be accustomed to eating a variety of foods [82]. 
Recommendations on infant nutrition are based on the nutrient gap between the composition and volume of breast milk ( $630 \mathrm{ml} /$ day) after approximately six months of exclusive breastfeeding and also on the physiology of infant nutritional requirements [38].

Gastrointestinal flora influence health [10], but the composition of flora can be adapted by consuming prebiotics or probiotics [30]. Prebiotics are nondigestible substances that stimulate the growth of health-promoting bacteria in the colon, such as bifidobacteria [15, 21, 34]. They are live microbial feed supplements which improve the intestinal microbial balance [33].

Immediately after birth, bacterial colonisation of the infant's gut begins with bifidobacteria and lactobacilli [70]. These organisms are transferred from the maternal microbial flora in the genital tract and colon during delivery, and also from the environment [33].

Gut-associated immune tissue comprises $80 \%$ of the immune system, making the composition of intestinal flora an important factor in the immune system [46]. It is believed that the onset of many diseases possibly relates to disruption of the early colonisation of the gut [21]. Preterm infants have delayed colonisation of the gut with beneficial flora by three to four weeks, but colonisation with pathogens occurs earlier and contributes to health problems, such as necrotising enterocolitis (NEC) [66].

Breastfed infants are often healthier than formula-fed infants and can fight infections better [36]. Breast milk naturally contains prebiotics (oligosaccharides) at a level of 10-12 g/l. These oligosaccharides favour the growth of bifidobacteria in the colon. Exclusively breastfed infants have higher numbers of bifidobacteria and lower numbers of the Escherichia coli bacteria, while formula-fed infants harbour equal amounts of these different types of intestinal flora $[32,45,68,70]$.

There are various reasons for this, including the lower content and different composition of proteins in breast milk the lower phosphorous content, and oligosaccharides and mediators of immune function that are found in human milk. Infant formula lacks these benefits [10]. Breastfeeding protects against allergies and infections. This is thought to be partly due to the presence of more bifidobacteria in the gut. Therefore, breast milk stimulates the development of the infant's immune system [30]. Bifidus-dominated flora is protective as it activates the immune system and inhibits invading pathogens that can cause infections. There is also some evidence that infants who suffer from allergies have less bifidobacteria and lactobacilli in their colons [30]. Often, infant formula is supplemented with probiotics and prebiotics to help promote the development of a bifidus-dominated flora, with the goal of creating an intestinal flora composition that is similar to that of a breastfed infant [32].

Docosahexaenoic acid, DHA, is a long chain omega-3 fatty acid that is found throughout the body. More specifically, DHA is an important structural fat in the brain and eyes and is a key component of the heart. DHA, ARA a natural components of breast milk, are important for brain and eye development and function. Arachidonic acid (ARA) is an omega- 6 fatty acid that is added with DHA to infant formulas.

\section{Complementary and Weaning Foods}

Complementary food is semi-solid porridges that are given from six to eight months, while weaning food comprises small portions of solid food given until 12 months, when family foods are integrated. These foods should be hygienically prepared and culturally appropriate $[18,44]$. Complementary foods should be introduced one at a time to identify allergies and intolerances, and according to the developmental stage of the infant, starting with cereals, porridge with milk, puréed vegetables or fruit and then progressing to a mixed diet in mashed form. The sequence in which foods are introduced is not important [69].

Introducing vegetables before fruits may increase vegetable acceptance [69]. According to Sullivan et al, infants develop taste preferences to foods in relation to frequency of exposure. Vegetable intake significantly increases after 10 days exposure and infants who are fed breast milk demonstrate greater increases in vegetable intake than formula-fed infants [71].

To encourage and establish healthy eating habits, parents and caregivers should offer a wide variety of dark green, leafy and deep yellow vegetables and colourful fruits. Pure fruit juices (115-170 ml/day) may be introduced into the diet after six months of age [50].

During the complementary feeding period, $>90 \%$ of the iron requirements of a breast-fed infant must be met by complementary foods, which should provide sufficient bioavailable iron. Cow's milk is a poor source of iron and should not the predominant drink before 12 months, although small volumes may be added to complementary foods [11]. A limited gastric capacity and high nutrient requirements for energy and nutrients create the need for small, frequent, energy- and nutrient-dense meals [38]. The frequency of feeding should gradually increase from two to four meals per day by approximately six months of age, to four to six meals (including snacks in addition to milk feeds), when the infant is older than six months [51].

\subsection{Timing of Weaning}

The WHO recommends six months of exclusive breastfeeding to protect infants from gastroenteritis-related morbidity and mortality [81]. However, there have been questions as to whether these recommendations apply to developed countries where the risks from episodes of gastroenteritis are minimal $[43,49,53]$ and whether infants who are weaned before six months are at risk of micronutrient deficiencies [43, 63]. There are no reported disadvantages in beginning to wean infants onto solid foods between four and six months in developed countries [27]. The European Society for Pediatric Gastroenterology, 
Hepatology and Nutrition (ESPGHAN) and the North American Society for Pediatric Gastroenterology, Hepatology and Nutrition (NASPGHAN) recommend exclusive breastfeeding for approximately six months, weaning from four to six months and continuous breastfeeding for two years [11].

\subsection{Allergens in the Diet}

Current evidence does not support maternal dietary restrictions during pregnancy or lactation. Furthermore, there is not a strong relationship between the timing of the introduction of complementary foods and the development of atopic disease [11]. According to ESPGHAN, there is no convincing evidence that avoidance or the delayed introduction of potentially allergenic foods, such as fish and eggs, milk used in foods and cooking, cheese, yoghurt, wheat and other gluten-containing cereals reduces allergies, either in infants considered to be at increased risk, or in those who are not considered to be at risk.

Both early $(<4$ months) and late $(>7$ months $)$ introduction of gluten should be avoided. Gluten should be gradually introduced while the infant is still being breastfed as this may reduce the risk of celiac disease, type 1 diabetes mellitus and wheat allergy [11].

\subsection{Nutritional Requirements}

The approach of the Food and Nutrition Board of the Institute of Medicine of the United States to formulate the dietary reference intakes (DRIs) represents a paradigm shift from avoiding deficiency states, as determined by clinical manifestation, to maximising health and improving quality of life. Reference heights for the DRIs are $64 \mathrm{~cm}$ for 2-6 months of age and $72 \mathrm{~cm}$ for 7-11 months of age, while reference weights are $7 \mathrm{~kg}$ for 2-6 months and $9 \mathrm{~kg}$ for 7-11 months [16]. Most mixed diets, which are adequate in quantity and fed with appropriate frequency, will provide the necessary requirements [38].

Energy intakes are calculated based on an assumed average breast milk intake of $\sim 630 \mathrm{ml}$ per day [38]. Therefore, energy needs range between $600 \mathrm{kcal} /$ day (six to eight months), $700 \mathrm{kcal} /$ day (nine to 11 months), and 900 $\mathrm{kcal} /$ day (12-24 months) [79]. The weaning diets of infants in developed countries are normally high in protein with a protein: energy ratio of $2.5-3$, because of a high protein density of complementary foods and a low percentage of infants still being breastfed after six months. There is some evidence that infants in the higher quantities of consumption seem to carry a higher risk of becoming obese later in life. More than $14 \%$ of energy from proteins in the 8 to 24-month period may cause an early adiposity rebound and the development of overweight in young children. A low protein: energy ratio in many developing countries, where the available complementary food is mostly cereals, is also problematic. When the protein concentration of weaning foods falls below the lower limits of human milk (1 g protein/100 kcal), the infant's dietary requirements cannot be met [8].

A dietary fat intake of $30-45 \%$ of total energy is recommended. The American Heart Association (AHA) has a limit of $40 \%$ fat of total energy with an emphasis on a more liberal intake of unsaturated fat and a focus on ensuring adequate intakes of omega- 3 fatty acids in infants and children. There is also an emphasis on foods that are rich in nutrients and provide increased amounts of dietary fibre. The AHA further recommends diets that are low in saturated and trans-fats and healthy foods such as fruit, vegetables, whole grains, legumes, low-fat dairy products, fish, poultry and lean meats [76].

Table 1. The daily nutrient requirements, expressed as dietary reference intakes or recommended daily allowances, for infants from six to 12 months of age [16,38]

\begin{tabular}{llll}
\hline Nutrient & $\begin{array}{l}\text { DRI/RDA for } \\
\text { infants 6-12 } \\
\text { months }\end{array}$ & $\begin{array}{l}\text { Assumed } \\
\text { intake from } \\
\text { milk }\end{array}$ & $\begin{array}{l}\text { Required } \\
\text { from } \\
\text { complementa } \\
\text { ry foods }\end{array}$ \\
\hline Energy (kCal) & & & \\
Girls & 676 & 400 & 276 \\
Boys & 743 & 400 & 343 \\
Total fat (g) & 30 & 21.2 & 8.8 \\
Protein (RDA) (g) & 13.5 & 9.6 & 3.9 \\
Calcium (mg) & 152 & 270 & 118 \\
Iron (RDA) (mg) & 11 & 0.5 & 10.4 \\
Zinc (RDA) (mg) & 3 & 2.2 & 0.7 \\
Vitamin A (mg) & 500 & 86.4 & 413 \\
Vitamin C (mg) & 50 & 26.8 & 23.2 \\
Vitamin D (mg) & 5 & 1.2 & 3.8 \\
Vitamin E (mg) & 5 & 2.4 & 2.6 \\
Thiamine (mg) & 0.3 & 0.056 & 0.244 \\
Riboflavin (mg) & 0.4 & 0.164 & 0.236 \\
Niacin (mg) & 4 & 1.2 & 2.8 \\
Pyridoxine (mg) & 0.3 & 0.036 & 0.264 \\
Folic acid (mg) & 80 & 20 & 60 \\
\hline
\end{tabular}

DRI: dietary reference intakes, RDA: recommended daily allowance

The DRIs for total fat are $31 \mathrm{~g}$ /day from birth to six months and $30 \mathrm{~g}$ /day from 6 to 12 months (Table 1). The DRIs for the essential fatty acids linoleic acid (n-6) and $\alpha$ linolenic acid (n-3) are 4.6 and $0.5 \mathrm{~g}$ /day respectively for 6 to 12-month-old infants [16]. Currently, there are no DRIs for the long-chain polyunsaturated fatty acids eicosahexaenoic acid, docosahexaenoic acid and arachidonic acid, although these are particularly important in brain development and retinal function [58].

\section{Global Standard for the Composition of Infant Formula}

The composition of infant formulae should serve to meet the particular nutritional requirements and to promote normal growth and development of the infants for whom they are intended. International Expert Group (IEG) demonstrated recommendations on the compositional 
requirements for a global infant formula standard. The IEG concludes that infant formulae should only contain components in such amounts that serve a nutritional purpose or provide another benefit. Minimum and maximum values of nutrient contents in infant formulae are suggested with the goal to provide safe and nutritionally adequate infant formula products that meet the nutritional requirements of healthy babies as shown in Table 2 . The IEG considered that such minimum and maximum values should be based, where available, on adequate scientific data on infant requirements and the absence of adverse effects [6].

Table 2. Proposed compositional requirements of infant formula

\begin{tabular}{|c|c|c|c|}
\hline Component & Unit & Minimum & Maximum \\
\hline Energy & $\mathrm{kcal} / 100 \mathrm{ml}$ & 60 & 70 \\
\hline \multicolumn{4}{|l|}{ Proteins } \\
\hline Cows' milk protein & $\mathrm{g} / 100 \mathrm{kcal}$ & $1.8^{*}$ & 3 \\
\hline Soy protein isolates & $\mathrm{g} / 100 \mathrm{kcal}$ & 2.25 & 3 \\
\hline Hydrolyzed cows' milk protein & $\mathrm{g} / 100 \mathrm{kcal}$ & $1.8 \dagger$ & 3 \\
\hline \multicolumn{4}{|l|}{ Lipids } \\
\hline Total fat & $\mathrm{g} / 100 \mathrm{kcal}$ & 4.4 & 6.0 \\
\hline Linoleic acid & $\mathrm{g} / 100 \mathrm{kcal}$ & 0.3 & 1.2 \\
\hline$\alpha$-linolenic acid & $\mathrm{mg} / 100 \mathrm{kcal}$ & 50 & NS \\
\hline Ratio linoleic/ & & $5: 1$ & $15: 1$ \\
\hline \multicolumn{4}{|l|}{$\alpha$-linolenic acids } \\
\hline Lauric + myristic acids & $\%$ of fat & NS & 20 \\
\hline Trans fatty acids & $\%$ of fat & NS & 3 \\
\hline Erucic acid & $\%$ of fat & NS & 1 \\
\hline \multicolumn{4}{|l|}{ Carbohydrates } \\
\hline Total carbohydrates $\ddagger$ & $\mathrm{g} / 100 \mathrm{kcal}$ & 9.0 & 14.0 \\
\hline \multicolumn{4}{|l|}{ Vitamins } \\
\hline Vitamin A & $\begin{array}{l}\mu \mathrm{g} \mathrm{RE} / 100 \\
\mathrm{kcal} \S\end{array}$ & 60 & 180 \\
\hline Vitamin $\mathrm{D}_{3}$ & $\mu \mathrm{g} / 100 \mathrm{kcal}$ & 1 & 2.5 \\
\hline Vitamin E & $\begin{array}{l}\operatorname{mg} \alpha- \\
\mathrm{TE} / 100 \mathrm{kcal}^{\|}\end{array}$ & 0.59 & 5 \\
\hline Vitamin K & $\mu \mathrm{g} / 100 \mathrm{kcal}$ & 4 & 25 \\
\hline Thiamin & $\mu \mathrm{g} / 100 \mathrm{kcal}$ & 60 & 300 \\
\hline Riboflavin & $\mu \mathrm{g} / 100 \mathrm{kcal}$ & 80 & 400 \\
\hline Niacin\# & $\mu \mathrm{g} / 100 \mathrm{kcal}$ & 300 & 1500 \\
\hline Vitamin $\mathrm{B}_{6}$ & $\mu \mathrm{g} / 100 \mathrm{kcal}$ & 35 & 175 \\
\hline Vitamin $\mathrm{B}_{12}$ & $\mu \mathrm{g} / 100 \mathrm{kcal}$ & 0.1 & 0.5 \\
\hline Pantothenic acid & $\mu \mathrm{g} / 100 \mathrm{kcal}$ & 400 & 2000 \\
\hline Folic acid & $\mu \mathrm{g} / 100 \mathrm{kcal}$ & 10 & 50 \\
\hline Vitamin C & $\mathrm{mg} / 100 \mathrm{kcal}$ & 8 & 30 \\
\hline Biotin & $\mu \mathrm{g} / 100 \mathrm{kcal}$ & 1.5 & 7.5 \\
\hline \multicolumn{4}{|l|}{ Minerals and trace elements } \\
\hline Iron (formula based on cows' milk & & & \\
\hline protein and protein hydrolysate) & $\mathrm{mg} / 100 \mathrm{kcal}$ & $0.3 * *$ & 1.3 \\
\hline $\begin{array}{l}\text { Iron (formula based on soy protein } \\
\text { isolate) }\end{array}$ & $\mathrm{mg} / 100 \mathrm{kcal}$ & 0.45 & 2.0 \\
\hline Calcium & $\mathrm{mg} / 100 \mathrm{kcal}$ & 50 & 140 \\
\hline $\begin{array}{l}\text { Phosphorus (formula based on cows' } \\
\text { milk protein and protein hydrolysate) }\end{array}$ & $\mathrm{mg} / 100 \mathrm{kcal}$ & 25 & 90 \\
\hline $\begin{array}{l}\text { Phosphorus (formula based on soy } \\
\text { protein isolate) }\end{array}$ & $\mathrm{mg} / 100 \mathrm{kcal}$ & 30 & 100 \\
\hline Ratio calcium/phosphorus & $\mathrm{mg} / \mathrm{mg}$ & $1: 1$ & $2: 1$ \\
\hline
\end{tabular}

\begin{tabular}{llcc}
\hline Component & Unit & Minimum & Maximum \\
\hline Magnesium & $\mathrm{mg} / 100 \mathrm{kcal}$ & 5 & 15 \\
Sodium & $\mathrm{mg} / 100 \mathrm{kcal}$ & 20 & 60 \\
Chloride & $\mathrm{mg} / 100 \mathrm{kcal}$ & 50 & 160 \\
Potassium & $\mathrm{mg} / 100 \mathrm{kcal}$ & 60 & 160 \\
Manganese & $\mu \mathrm{g} / 100 \mathrm{kcal}$ & 1 & 50 \\
Fluoride & $\mu \mathrm{g} / 100 \mathrm{kcal}$ & $\mathrm{NS}$ & 60 \\
Iodine & $\mu \mathrm{g} / 100 \mathrm{kcal}$ & 10 & 50 \\
Selenium & $\mu \mathrm{g} / 100 \mathrm{kcal}$ & 1 & 9 \\
Copper & $\mu \mathrm{g} / 100 \mathrm{kcal}$ & 35 & 80 \\
Zinc & $\mathrm{mg} / 100 \mathrm{kcal}$ & 0.5 & 1.5 \\
Other substances & & & \\
Choline & $\mathrm{mg} / 100 \mathrm{kcal}$ & 7 & 50 \\
Myo-inositol & $\mathrm{mg} / 100 \mathrm{kcal}$ & 4 & 40 \\
L-carnitine & $\mathrm{mg} / 100 \mathrm{kcal}$ & 1.2 & $\mathrm{NS}$ \\
\hline
\end{tabular}

*The determination of the protein content of formulae based on nonhydrolyzed cow's milk protein with a protein content between 1.8 and 2.0 $\mathrm{g} / 100 \mathrm{kcal}$ should be based on measurement of true protein ([total N $\mathrm{NPN}] \times 6.25)[4]$

$\dagger$ Formula based on hydrolyzed milk protein with a protein content less than $2.25 \mathrm{~g} / 100 \mathrm{kcal}$ should be clinically tested.

$\$$ Sucrose (saccharose) and fructose should not be added to infant formula. $\S 1 \mathrm{~m} \mathrm{~g} \mathrm{RE}($ retinol equivalent $)=1 \mathrm{mg}$ all-trans retinol $=3.33 \mathrm{IU}$ vitamin $\mathrm{A}$. Retinol contents shall be provided by preformed retinol, while any contents of carotenoids should not be included in the calculation and declaration of vitamin A activity.

${ } 1 \mathrm{mg} \alpha$-TE ( $\alpha$-tocopherol equivalent $)=1 \mathrm{mg} \mathrm{d}$ - $\alpha$-tocopherol.

I Vitamin E content shall be at least $0.5 \mathrm{mg} \alpha$-TE per g PUFA, using the following factors of equivalence to adapt the minimal vitamin $\mathrm{E}$ content to the number of fatty acid double bonds in the formula: $0.5 \mathrm{mg} \alpha-\mathrm{TE} / \mathrm{g}$ linoleic acid (18:2n-6); $0.75 \mathrm{mg} \alpha$-TE/g $\alpha$-linolenic acid (18:3n-3); $1.0 \mathrm{mg}$ $\alpha-\mathrm{TE} / \mathrm{g}$ arachidonic acid (20:4n-6); $1.25 \mathrm{mg} \alpha-\mathrm{TE} / \mathrm{g}$ eicosapentaenoic acid (20:5n-3); $1.5 \mathrm{mg} \alpha$-TE/g docosahexaenoic acid (22:6n-3).

\#Niacin refers to preformed niacin.

**In populations where infants are at risk of iron deficiency, iron contents higher than the minimum level of $0.3 \mathrm{mg} / 100 \mathrm{kcal}$ may be appropriate and recommended at a national level.

NS not specified.

\section{Probiotic-Supplemented Formula}

The overall health benefit and efficacy of adding probiotics to infant formula remains to be demonstrated in large randomised clinical trials (RCTs). A clinical report by the American Academy of Paediatrics reviewed the currently known health benefits of probiotic and prebiotic products, including those that are added to commercially available infant formula and other food products for children [21].

The report states that the use of probiotics has been shown to be modestly effective in RCTs in treating acute viral gastroenteritis in healthy children, and preventing antibiotic-associated diarrhoea in healthy children. There is some evidence that probiotics prevent NEC in very low birth weight infants (birth weight between 1000-1500 g), but more studies are needed.

The committee on nutrition of the European Society for Pediatric Gastroenterology, Hepatology and Nutrition (ESPGHAN) systematically reviewed published evidence relating to the safety and health effects of the 
administration of formula that was supplemented with probiotics and/or prebiotics, and compared it to that on unsupplemented formula [12].

The committee concluded that currently there are no safety concerns regarding feeding probiotic and/or prebiotic-supplemented formula to healthy infants, but there are insufficient data to recommend the routine use of probiotic and/or prebiotic supplemented formula. They acknowledge the importance of more research in this field.

An effective probiotic must be nonpathogenic and nontoxic and exert a beneficial effect on the host. Moreover it should be capable of surviving passage through the gastrointestinal tract, particularly the harsh environmental conditions in the human stomach and small intestine. Probiotic supplementation in infant formula has shown that some strains may persist in the infant gut and lower stool $\mathrm{pH}[33]$.

\section{Probiotics in the Treatment or Prevention of Selected Clinical Diseases}

\subsection{Infectious Diarrhoea}

Results of published RCTs have indicated that there is modest benefit when giving probiotics to prevent acute gastrointestinal tract infections in healthy infants and children. The strains of probiotics that were used included Lactobacillus rhamnosus GG (LGG), Streptococcus thermophilus, L. casei, Bifidobacterium lactis, or L. reuteri mixed with milk or infant formula or given as an oral supplement. Rotavirus was the most common cause of acute diarrhoea in the RCTs [1].

Results of meta-analyses [13,34,48] and a Cochrane review [74] have been published on the benefit of probiotics in treating acute infectious diarrhoea in children. These reports indicate that probiotics reduce the number of diarrheal stools and the duration (approximately by one day) of the diarrhoea.

\subsection{Antibiotic-Associated Diarrhoea}

Reviews showed that use of a probiotic-supplemented formula reduces the incidence of antibiotic-associated diarrhoea. B. lactis and S. thermophilus had the greatest effect [1, 46]. A meta-analysis [35] of published results from RCTs on probiotic use in the prevention of antibioticassociated diarrhoea in children indicated a beneficial effect. Children received either a probiotic-supplemented formula or a separate probiotic as preventive treatment. No RCTs have been published that have investigated the effect of probiotics when treating antibiotic-associated diarrhoea in children. Thus, their use cannot be recommended [21].

\subsection{Infantile Colic}

Formula with B. lactis BL999 and LPR, L. reuteri or
LGG is also not associated with a decreased frequency of colic, crying and irritability in children younger than six months [12], but the use of B. lactis and $S$. thermophilus is associated with a lesser frequency of colic in children older than six months. No effect was observed with the use of $B$. lactis alone, L. reuteri or L. salivarius [12].

It is speculated that probiotics may change patterns of fermentation in the colon, leading to less gas or water fermentation, which may improve gastrointestinal tolerance [45].

Further confirmatory RCTs are required to recommend the routine use of probiotics in the treatment of infantile colic in both breastfed and formula-fed infants [21].

\subsection{Respiratory Infections}

Limited evidence shows that formula that is supplemented with $B$. lactis does not decrease the risk of respiratory infections, and B. longhum BL999 and $L$. rhamnosus LPR are not associated with a decreased use of antibiotics in infants younger than six months [12]. There is also limited evidence to show that a combination of $B$. lactis and $\mathrm{S}$. thermophilus or L. reuteri is associated with a decreased use of antibiotics in children older than six months [12].

\subsection{Allergies}

Insufficient evidence was found to recommend the use of probiotics in infant feeds to prevent food allergies or sensitivities [15, 21]. The ESPGHAN concluded that limited available data suggest that the probiotics studied ( $B$. longhum BL999 and LPR) had no effect on allergies. However, the committee considered that there is too much uncertainty to draw reliable conclusions from the available data [12].

\section{Prebiotic-Supplemented Formula}

Examples of prebiotic oligosaccharides include fructooligo-saccharides (FOS), inulin, galactooligosaccharides (GOS), and soybean oligosaccharides [1]. Supplemented bifidobacterial species colonise the intestine of infants who receive the supplementation [45]. The use of oligosaccharides in formula results in higher bifidobacteria counts in stools. Fecal lactobacilli can also increase, but the clinical benefits are not clear [12, 70]. Prebioticsupplemented formula has a limited effect on the reduction of pathogenic bacteria. The response to prebiotics in formula is thought to be dependent on the healthy gut flora prior to supplementation. Some studies show a dosedependent effect of the prebiotics on the stimulating effect of bifidobacteria and lactobacilli growth [70].

Supplementation of formula with a mixture of FOS/GOS has no negative effects. There is a modest improved effect on growth in children younger than six months [12]. However, it is associated with a slightly higher weight gain in children older than six months [70]. 
The use of prebiotics in formula can potentially reduce the stool $\mathrm{pH}$ of children younger than six months $[12,70]$. Limited evidence shows that such formula potentially leads to increased stool frequency and softer stools, similar to that of breastfed infants $[12,70]$.

Furthermore, infants who receive GOS/FOS might have fewer episodes of infections and require fewer antibiotics. The total number of infections, cumulative incidence of infections and the number of recurring infections during the first six months might be reduced [68]. However, evidence regarding the use of prebiotics in the prevention of allergies is inconclusive [14].

Prebiotic-supplemented infant formula is mostly well tolerated. To date, these products seem to be safe in healthy infants. FOS and GOS may be voluntarily added to infant formula $(<0.8 \mathrm{~g} / 100 \mathrm{ml})$ in a ratio of $90 \%$ GOS: $10 \%$ FOS. The Food and Agricultural Organization (FAO) of the United Nations supports the supplementation of formula with prebiotics in infants aged five months and older, as these infants will have a mature immune system and intestinal colonisation.

\section{Prebiotic- and Probiotic- Supplemented Formula in Preterm Neonates}

There is limited evidence that the supplementation of preterm formula with FOS/GOS is well tolerated, increases the bifidobacteria stool colony counts, decreases the growth of pathogenic bacteria, improves gastrointestinal transit time, and softens and acidifies stools to a degree that is similar to that in breastfed infants. Therefore, supplementation with prebiotics is safe, but routine use is not recommended [66]. Premature infants have inadequate colonisation of the gut for various reasons. It is suspected that the establishment and composition of intestinal flora in preterm infants plays a role in the development of NEC. Theoretically, administration of probiotics to preterm infants should reduce gut pathogens, improve the structure and function of the gut, reduce the need for parenteral nutrition, facilitate enteral nutrition, improve the gut mucosal barrier function, decrease sepsis and antibiotic use, and prevent NEC [46].

\section{DHA, ARA Supplemented Formula}

DHA is the most abundant omega- 3 fatty acid in the brain and the retina of the eye, representing about $97 \%$ and 93\% of all omega-3 fatty acids in the brain and eyes, respectively, and is important for healthy visual and mental development throughout infancy $[52,56,57,61]$. The brain grows rapidly during the last months of gestation and throughout the first years of life. This growth spurt is a time of rapid DHA accumulation in the brain [2, 37,60].

An infant's ability to produce DHA may be inconsistent and inefficient. Infant blood DHA levels decrease significantly following birth unless the infant receives DHA either through breast milk or supplemented infant formula $[9,19,31,54,55,72,75,77]$. Breast milk is the optimal method for infant feeding. Breast milk always contains the long chain polyunsaturated fatty acids, DHA and ARA [67]. Recommendations have been made by several expert groups for infant formulas containing DHA and ARA [3, 6 , $7,29,65,78]$.

Infants rapidly accumulate DHA from their mother during the last months of gestation. Infants born prematurely do not have time to accumulate DHA to the same level as their full-term counterparts. When fed formula supplemented with DHA and ARA, preterm infants achieved normal growth in terms of weight, length and head circumference [17, 39,40,59], and showed improved visual and mental development compared to the infants fed formula not supplemented with DHA and ARA [59].

Many studies have demonstrated improved mental development for infants fed DHA and ARA-supplemented formula compared to those receiving unsupplemented formula. These benefits extend well beyond the period of supplementation and continue into childhood [22, 24, 64]. Term infants fed DHA (0.36\%) and ARA (0.72\%) supplemented formula scored 7 points higher on the Bayley Mental Development Index at 18 months than those fed unsupplemented formula [22].

In a follow-up study of those same children at age 4, visual acuity and verbal IQ scores were higher in those children who had received supplemented formula compared with those who received formula lacking DHA and ARA [24]. Infants who were breastfed and then weaned to formula supplemented with DHA and ARA demonstrated more mature visual acuity than those breast-fed infants weaned to non-supplemented formula [20,23]. Infants fed DHA-supplemented formula exhibited better visual acuity than that of the non-supplemented infants (equivalent to 1.5 lines on the eye chart), and similar to that of breast-fed infants [25, 26, 73]. One study showed that infants fed formula supplemented with DHA $(0.36 \%)$ and ARA $(0.72 \%)$ had fewer episodes of bronchiolitis and bronchitis at age 5, 7 , and 9 months compared to infants fed non-supplemented formula [62].

Infants fed formula supplemented with DHA and ARA had significantly lower blood pressure compared to infants fed non-supplemented formula, similar to that of breast-fed infants. Because blood pressure tends to track from childhood into adult life, it has been suggested that early intake of DHA and ARA may reduce the risk of cardiovascular disease later in life [47].

\section{Conclusion}

Weaning should start between four to six months of age and breastfeeding should continue throughout weaning for at least two years, together with the timely introduction of adequate amounts of complementary foods. Initially, meals should be provided two to three times per day, and later 
three to four times per day with additional nutritious snacks, such as a piece of fruit or bread, offered one to two times per day, as desired [80].

The prebiotics and probiotics that are now being added to commercial infant formula are classified as GRAS (generally regarded as safe) by the FDA. The addition of probiotics to powdered infant formula has not been demonstrated to be harmful to healthy term infants. However, evidence of clinical efficacy regarding their addition is insufficient to recommend the routine use of such formula [12, 21].

The ESPGHAN committee on nutrition has concluded that at present, there are insufficient data to recommend the routine use of probiotic and/or prebiotic-supplemented formula. Yet the administration of probiotic (single or in combination) supplementation to infant or follow-on formula and given beyond early infancy, may be associated with some clinical benefits. These include a reduction in the risk of nonspecific gastrointestinal infections, a reduced risk of antibiotic use and a lower frequency of colic or irritability. Reviewed studies have varied with regard to methodological quality, the specific strains studied, the duration of the interventions and the doses used. The FAO supports the use of prebiotics in infant formula for infants aged five months and older, as they have a more mature immune system. Products containing prebiotics or probiotics are not recommended for immune compromised infants, ill preterm neonates and children with indwelling medical devices [21].

For formula fed infants it is suggested arachidonic acid be given with DHA at a ratio of 1.5:1 (ARA: DHA). Recommendation recently published by international experts in the Journal of Perinatal Medicine state that infant formulas should include DHA level between $0.2-0.5 \%$ and the amount of ARA should be at least equal to the DHA level. The experts also recommend at least $0.25 \% \mathrm{DHA}+\mathrm{ARA}$ is necessary to achieve functional developmental benefits [5].

\section{References}

[1] A.C. Uwaegbute, and D.O. Nndnyehtgo, "Differences in the infant-feeding practices in urban and rural Nigeria. Journal of Nutritional Education", 1987, vol. 19, pp.83-89.

[2] A.K. Dutta-Roy, "Transport mechanisms for long-chain polyunsaturated fatty acids in the human placenta", Am J Clin Nutr, 2000, vol. 71, pp.315S-22S.

[3] A.P. Simopoulos, "Workshop on the essentiality of and recommended dietary intakes for omega- 6 and omega-3 fatty acids", J Am Coll Nutr, 1999, vol. 18(5), pp. 487-9.

[4] Association of Official Agricultural Chemists (AOAC). Official methods of the Association of Official Agricultural Chemists (AOAC) international, 17th Edition. 2002.

[5] B. Koletzko, E. Lien and C. Agostoni, "The roles of longchain polyunsaturated fatty acids in pregnancy, lactation and infancy", Review of current knowledge and consensus recommendations.J Perinat Med 2008, vol. 36, pp.5-14.
[6] B. Koletzko," Global standard for the composition of infant formula: recommendations of an ESPGHAN coordinated international expert group", J Pediatr Gastroenterol Nutr 2005, vol. 41, pp.584-99.

[7] B. Koletzko, "Long chain polyunsaturated fatty acids (LCPUFA) and perinatal development. Acta Paediatr", 2001, pp. $90-460$.

[8] C. Agostoni, E. Riva, M. Giovannini, Complementary food: international, comparison on protein and energy requirements/intakes. Nestle Nutr Workshop Ser Pediatr Program. 2006, vol. 58, pp.147-156, discussion pp.156-159.

[9] C. Agostoni, "Neurodevelopmental quotient of healthy term infants at 4 months and feeding practice", the role of longchain polyunsaturated fatty acids. Pediatr Res, 1995, pp. 38262.

[10] C. Agostoni, I. Axelsson and C. Braegger, "Probiotic bacteria in dietetic products for infants: a commentary by the ESPGHAN Committee on Nutrition", J Pediatr Gastroenterol Nutr. 2004, vol. 38(4), pp.365-374.

[11] C. Agostoni, T. Decsi and M. Fewtrell, "Medical position paper on complementary feeding: a commentary by the ESPGHAN Committee on Nutrition", J Pediatr Gastroenterol Nutr. 2008, vol. 46(1), pp.99-110.

[12] C. Braegger, A. Chmielewska and T. Decsi, "Supplementation of infant formula with probiotics and/or prebiotics: a systematic review and comment by the ESPGHAN committee on nutrition", J Pediatr Gastroenterol Nutr. 2011, vol. 52(2), pp. 238-250.

[13] C.W. Van Niel, C. Feudtner, MM. Garrison and DA. Christakis, "Lactobacillus therapy for acute infectious diarrhea in children", a meta-analysis. Pediatrics. 2002, vol. 109(4), pp.678-684.

[14] D.A. Osborn and J.K. Sinn, "Prebiotics in infants for prevention of allergic disease and food hypersensitivity", [Cochrane review]. In The Cochrane Library, Issue 4, 2007. Oxford: Update Software.

[15] D.A Osborn and J.K, Sinn, "Probiotics in infants for prevention of allergic disease and food hypersensitivity", [Cochrane review]. In The Cochrane Library, Issue 4, 2007. Oxford: Update Software.

[16] Dietary reference intakes for calcium, phosphorous, magnesium, Vitamin D, and fluoride (1997); dietary reference intakes for thiamin, riboflavin, niacin, Vitamin B6, folate, Vitamin B12, pantothenic acid, biotin and choline (1998); dietary reference intakes for Vitamin C, Vitamin E, selenium and carotenoids (2000); dietary reference intakes for Vitamin A, Vitamin K, arsenic, boron, chromium, copper, iodine, iron, manganese, molybdenum, nickel, silicon, vanadium and zinc (2001); dietary reference intakes for energy, carbohydrate, fiber, fat, fatty acids, cholesterol, protein and amino acids (2002/2005); and dietary reference intakes for calcium and Vitamin D (2011). USDA [homepage on the Internet]. c2012. Available from: http://fnic.nal.usda.gov/dietary-guidance/dietary-referenceintakes/dri-tables.

[17] D.L. O'Connor, "Growth and development in preterm infants fed long-chain polyunsaturated fatty acids: a prospective, randomized controlled trial. Pediatrics", 2001, vol. 108(2), pp.359-71. 
[18] D.M. Stephenson, J.M. Gardner, S.P. Walker and A. Ashworth, "Weaning-food viscosity and energy density: their effects on ad libitum consumption and energy intakes in Jamaican children", Am J Clin Nutr. 1994, vol. 60(4), pp.465-469.

[19] D.R. Hoffman, "Docosahexaenoic acid in red blood cells of term infants receiving two levels of long-chain polyunsaturated fatty acids", J Pediatr Gastroenterol Nutr 2006, vol. 42, pp.287-292.

[20] D.R. Hoffman, "Visual function in breast-fed term infants weaned to formula with or without long-chain polyunsaturates at 4 to 6 months", a randomized clinical trial. J Pediatr, 2003, vol. 142, pp.669-77.

[21] D.W. Thomas and F.R. Greer, "Probiotics and prebiotics in pediatrics", American Academy of Pediatrics Committee on Nutrition, American Academy of Pediatrics Section on Gastroenterology, Hepatology, and Nutrition. Pediatrics. 2010, vol. 126(6), pp.1217-1231.

[22] E.E. Birch, "A randomized controlled trial of early dietary supply of long-chain polyunsaturated fatty acids and mental development in term infants", Dev Med Child Neurol, 2000, vol. 42(3): pp.174-81.

[23] E.E. Birch, "A randomized controlled trial of long-chain polyunsaturated fatty acid supplementation of formula in term infants after weaning at 6 weeks of age", Am J Clin Nutr, 2002, vol. 75, pp.570-80.

[24] E.E. Birch, "Visual acuity and cognitive outcomes at 4 years of age in a double-blind, randomized trial of long-chain polyunsaturated fatty acid-supplemented infant formula", Early Hum Dev (Epub), 2007.

[25] E.E. Birch, "Visual acuity and the essentiality of docosahexaenoic acid and arachidonic acid in the diet of term infants", Pediatr Res, 1998, vol. 44(2), pp.201-9.

[26] E.E. Birch, "Visual maturation of term infants fed long-chain polyunsaturated fatty acid-supplemented or control formula for 12 month", Am J Clin Nutr, 2005, vol. 81, pp.871-9.

[27] European Food Safety Authority Panel on Dietetic Products, Nutrition and Allergies, "Scientific opinion on the appropriate age for introduction of complementary feeding of infants”, EFSA Journal. 2009, vol. 7(12), 1423.

[28] F. Megraud, G. Boudraa, K. Bessaoud, S. Bensid, F. Dabis, R. Soltana and M. Touhami, "Incidence of Campylobatter infection in infants in western Algeria and the possible protective role of breast feeding", Epidemiology and Infections 1990, vol. 105, pp.13-78.

[29] Food and Agriculture Organisation of the United Nations and the World Health Organization. "Lipids in early development", In: fats and Oils. Food and Nutrition Paper ISBN 92-5-103621-7 Chap. 7, 1993, pp.49-55. http://www.fao.org/docrep/V4700E/V4700E00.htm

[30] G. Boehm and G. Moro, "Structural and functional aspects of prebiotics used in infant nutrition", J Nutr. 2008, vol. 138(9), pp.1818S-1828S.

[31] G. Kohn, "Diet and essential fatty acid status of term infants", Acta Paediatr Suppl, 1994, vol. 402, pp.69-74.

[32] G. Veereman-Wauters, "Application of prebiotics in infant foods”, Br J Nutr. 2005, vol. 93(Suppl 1), pp. S57-S60.
[33] H. Parracho, A.L. McCartney and G.R. Gibson. "Probiotics and prebiotics in infant nutrition", Proc Nutr Soc. 2007, vol. 66(3), pp.405-411.

[34] H. Szajewska, J.Z. Mrukowicz, "Probiotics in the treatment and prevention of acute infectious diarrhea in infants and children", a systematic review of published randomized, double-blind, placebo-controlled trials. J Pediatr Gastroenterol Nutr. 2001, vol.33 (Suppl 2), pp.S17-S25.

[35] H. Szajewska, M. Ruszczynski and A. Radzikowski. "Probiotics in the prevention of antibiotic-associated diarrhea in children", a meta-analysis of randomized controlled trials. J Pediatr. 2006, vol. 149(3), pp.367-372.

[36] J. Chouraqui, D. Grathwohl and J. Labaune, "Assessment of the safety, tolerance, and protective effect against diarrhea of infant formulas containing mixtures of probiotics or probiotics and prebiotics in a randomized controlled trial", Am J Clin Nutr. 2008, vol. 87(5), pp.1365-1373.

[37] J. Dobbing and J. Sands, "Quantitative growth and development of the human brain", Arch Dis Child 1973, vol. 48 , pp.757-67.

[38] J. Van der Merwe, M. Kluyts, N. Bowley and M. Marais, "Optimizing the introduction of complementary foods in the infant's diet: a unique challenge in developing countries”, Matern Child Nutr. 2007, vol. 3(4), pp.259-270.

[39] J. Vanderhoof, "Evaluation of a long-chain polyunsaturated fatty acid supplemented formula on growth, tolerance, and plasma lipids in preterm infants up to 48 weeks postconceptual age", J Pediatr Gastroenterol, 1999, vol. 29, pp.318-26.

[40] J. Vanderhoof, "A multicenter long-term safety and efficacy trial of preterm formula supplemented with longchain polyunsaturated fatty acids", for The Multicenter Study Group. J Pediatr Gastroenterol Nutr, 2000, vol. 31(2), pp.121-7.

[41] J. Waterlow and P.R. Payne, "The protein gap", Nature 1975, vol. 258, pp.113-117.

[42] J. Waterlow. "Observations on the suckling's dilemma-a personal view", Journal of Human Nutrition 1981, vol. 35, pp. $85-98$.

[43] J.A. Lanigan, J.A. Bishop, A.C. Kimber and J. Morgan Systematic review concerning the age of introduction of complementary foods to the healthy full-term infant. Eur J Clin Nutr. 2001, vol. 55(5), pp.309-320.

[44] J.E. Kimmons, K.G. Dewey and E. Haque, "Behaviorchange trials to assess the feasibility of improving complementary feeding practices and micronutrient intake of infants in rural Bangladesh”, Food Nutr Bull. 2004, vol. 25(3), pp.228-238.

[45] J.M. Saavedra, A. Abi-Hanna, N. Moore and R.H. Yolken, "Long-term consumption of infant formulas containing live probiotic bacteria: tolerance and safety", Am J Clin Nutr. 2004, vol. 79(2), pp.261-267.

[46] J.M. Saavedra, "Use of probiotics in pediatrics: rationale, mechanisms of action, and practical aspects", Nutr Clin Pract. 2007, vol. 22(3), pp.351-365. 
[47] J.S. Forsyth, "Long chain polyunsaturated fatty acid supplementation in infant formula and blood pressure in later childhood", follow up of a randomised controlled trial. BMJ, 2003, vol. 326(7396), pp.953.

[48] J.S. Huang, A. Bousvaros and J.W. Lee, "Efficacy of probiotic use in acute diarrhea in children: a meta-analysis", Dig Dis Sci. 2002, vol. 47(11), pp.2625-2634.

[49] K.D. Foote and L.D. Marriott. "Weaning of infants", Arch Dis Child. 2003, vol. 88(6), pp. 488-492.

[50] K.G. Dewey, R.J. Cohen and N.G. Rollings. WHO technical background paper: "feeding of nonbreastfed children from 6 to 24 months of age in developing countries", Food and Nutr Bull. 2004, vol. 25(4), pp.377-402.

[51] K.H. Brown, "Breastfeeding and complementary feeding of children up to 2 years of age", Nestle Nutr Workshop Ser Pediatr Program. 2007, vol. 60, pp.1-10; discussion 10-3.

[52] L. Lauritzen, "The essentiality of long chain n-3 fatty acids in relation to development and function of the brain and retina”, Prog Lipid Res, 2001, vol. 40, pp.1-94.

[53] M. Fewtrell, A. Lucas and J.B. Morgan, "Factors associated with weaning in full term and preterm infants", Arch Dis Child Neonatal Ed. 2003, vol. 88(4), pp.F296-F301.

[54] M. Makrides, "Are long-chain polyunsaturated fatty acids essential nutrients in infancy? ", Lancet, 1995, vol. 345 (8963), pp.1463-8.

[55] M. Makrides, "Fatty acid composition of brain, retina, and erythrocytes in breast-fed and formula-fed infants", Am J Clin Nutr, 1994, vol. 60(2), pp.189-94.

[56] M. Martinez, "Tissue levels of polyunsaturated fatty acids during early human development", Pediatr, 1992, vol. 120, pp. S129-38.

[57] M.A. Crawford, "The role of essential fatty acids in neural development: implications for perinatal nutrition", Am J Clin Nutr, 1993, vol. 57, pp.703S-709S.

[58] M.S. Fewtrell, "Long-chain polyunsaturated fatty acids in early life: effects on multiple health outcomes", a critical review of current status, gaps and knowledge. Nestle Nutr Workshop Ser Pediatr Program. 2006, vol. 57, pp.203-14; discussion $215-221$.

[59] M.T. Clandinin, "Growth and development of preterm infants fed infant formulas containing docosahexaenoic acid and arachidonic acid', J Pediatr 2005, vol. 146, pp.461-8.

[60] M.T. Clandinin, "Intrauterine fatty acid accretion rates in human brain: implications for fatty acid requirements", Early Hum Dev, 1980, vol. 4, pp. 121-9.

[61] N. Jr. Salem, "Mechanisms of action of docosahexaenoic acid in the nervous system", Lipids, 2001, vol. 36, pp.94559.

[62] N. Pastor, "Infants fed docosahexaenoic acid- and arachidonic acid-supplemented formula have decreased incidence of bronchiolitis bronchitis the first year of life", Clin Pediatr (Phila), 2006, vol. 45(9), pp.850-5.

[63] N.F. Butte, M.G. Lopez-Alarcon and C. Garza. 'Nutrient adequacy of exclusive breastfeeding for the term infant during the first six months of life", Geneva: WHO; 2002.
[64] P. Willatts, "Effect of long-chain polyunsaturated fatty acids in infant formula on problem solving at 10 months of age", Lancet, 1998, vol. 352(9129), pp.688-91.

[65] P.J. Aggett, "Feeding preterm infants after hospital discharge", a commentary by the ESPGHAN Committee on Nutrition. J Pediatr Gastroenterol Nutr 2006, vol. 42, pp.596-603.

[66] R. Srinivasjois, S. Rao and S. Patole, "Prebiotic supplementation of formula in preterm neonates", a systematic review and meta-analysis of randomised controlled trials. Clin Nutr. 2009, vol. 28(3), pp.237-242.

[67] R. Yuhas, "Human milk fatty acid composition from nine countries varies most in DHA", Lipids 2006, vol. 41, pp.851-8.

[68] S. Arslanoglu, G.E. Moro and Boehm G. Early supplementation of prebiotic oligosaccharides protects formula-fed infants against infections during the first 6 months of life. J Nutr. 2007, vol. 137(11), pp.2420-2424.

[69] S. Gidding, B.A. Dennison and M.D. Cochair, "Recommendations for children and adolescents: a guide for practitioners", Pediatrics. 2005, vol. 117(2), pp.544-559.

[70] S. Rao, R. Srinivasjois and S. Patole, "Prebiotic supplementation in full-term neonates", a systematic review of randomized controlled trials. Arch Pediatr Adolesc Med. 2009, vol. 163(8), pp.755-764.

[71] S.A. Sullivan and L.L. Birch, "Infant dietary experience and acceptance of solid food", Pediatrics. 1994, vol. 93(2), pp.271-277.

[72] S.E. Carlson, "Visual acuity and fatty acid status of term infants fed human milk and formulas with or without docosahexaenoate and arachidonate from egg yolk lecithin", Pediatr Res, 1996, vol. 39, pp.882-8.

[73] S.E. Morale, "Duration of long-chain polyunsaturated fatty acids availability in the diet and visual acuity", Early Hum Dev, 2005, vol. 81(2), pp.197-203.

[74] S.J. Allen, B. Okoko and E. Martinez, "Probiotics for treating infectious diarrhoea", [Cochrane review]. In The Cochrane Library, Issue 2, 2004. Oxford: Update Software.

[75] S.M. Innis, "Blood lipid docosahexaenoic and arachidonic acid in term gestation infants fed formulas with high docosahexaenoic acid, low eicosapentaenoic acid fish oil", Lipids, 1996, vol. 31, pp.617-25.

[76] S.S. Gidding, B.A. Dennison and L.L. Birch, "Recommendations for children and adolescents", a guide for practitioners. Pediatrics. 2005, vol. 117(2), pp.555-559.

[77] T. Decsi and B. Koletzko, "Growth, fatty acid composition of plasma lipid classes, and plasma retinol and alphatocopherol concentration in full-term infants fed formula enriched with omega-6 and omega-3 long-chain polyunsaturated fatty acids", Acta Paediatr, 1995, vol. 84(7), pp.725-32.

[78] The Commission of the European Communities. Commission Directive 2006/141/EC of 22 December 2006 on infant formulae and follow-on formulae and amending Directive 1999/21/EC. Off J EU, Dec. 30, 2006:L401/1-33. 
[79] WHO. Feeding the non-breastfed child 6-24 months of age. Geneva: World Health Organization; 2004.

[80] WHO. Guiding principles for complementary feeding of the breastfed child. Geneva: WHO; 2004.

[81] World Health Organization. Global strategy for infant and young child feeding: the optimal duration of exclusive breastfeeding. 54th World Health Assembly; 2001.

[82] World Health Organization/United Nations Children's Fund. Global strategy for infant and young child feeding. Geneva: WHO; 2003. 